\title{
Journal of Scheduling (2017)
}

\author{
Edmund Burke ${ }^{1}$. Michael Pinedo ${ }^{2}$
}

Published online: 2 February 2017

(C) Springer Science+Business Media New York 2017

This year marks something of a landmark for the Journal of Scheduling: we have reached our 20th volume. The journal continues to act as one of the leading international publication venues for interdisciplinary research in all areas of scheduling. The scope of the journal cuts across both theory and practice, and it cuts across disciplinary boundaries. We are proud of the impact that the journal has had upon the scheduling research field and we will continue to build upon our high academic standards, with the goal of improving the journal even further. We have a particular emphasis upon encouraging high-quality review and survey papers, and we are keen to have a portfolio of papers that covers a wide range of scheduling areas. We continue to encourage focussed special issues. In 2016, we published Special Issues for New Challenges in Scheduling Theory and the Multidisciplinary International Scheduling Conference: Theory and Applications (MISTA).

During 2016, our journal has continued to perform well, particularly on article influence measures. According to eigenfactor.org, using its Article Influence score, the journal is ranked 21 st out of 70 journals in the Operations Research and Management Science category. Our ranking in the SCImago Journal and Country Rank is 39th out of 150 outlets in the category entitled, Management Science and Operations Research. Our current Thompson Reuters impact factor is 1.023 . The number of downloaded articles between January and October 2016 was 34,843 (the figure for November-December was not available at the time of writing). During 2016, we had 195 new submissions. The acceptance rate of submitted papers is currently running at around $25 \%$.

We are pleased to report that the average time it has taken us to turn around an original submission (the time taken between submission and first decision) has remained fairly consistent with last year. In 2015, we reported a figure of 70 days. Throughout 2016, it has been 73 days, a little more than two months. However, we are not complacent and we are aiming to bring the average turnaround time down to a lower level. This is an important goal for the Journal.

We would like to close this brief editorial by offering our sincere thanks to all those who have helped us make the Journal such a success. We are heavily dependent upon all our Associate Editors and reviewers. Their hard work and diligence underpin the success of the journal. The editorial team at Springer provides us with an outstanding level of support. We are particularly grateful to Venkat Ganesan, John Wolfe, Matthew Amboy and Neil Levine. During 2016, we said goodbye to our Production Editor, Supraja Yegnaraman. We would like to offer her our thanks for all her work over the years. We would also like to welcome our new Production Editor, Bharathi Ramachandran. Of course, the journal would not exist without the support of our readers and authors and we remain very grateful for this continued support.

$\triangle$ Edmund Burke

ekb@qmul.ac.uk

1 London, UK

2 New York, USA 